\title{
OPEN
}

\section{Author Correction: Evaluation of dental arch dimensions in 12 year- old Vietnamese children - A cross- sectional study of 4565 subjects}

Truong Manh Dung, Vo Truong Nhu Ngoc, Nguyen Hung Hiep, Truong Dinh Khoi, Vu Van Xiem, Thien Chu-Dinh, Artur Cieslar-Pobuda, Eleana Stoufi, Pau Loke Show $\mathbb{D}$, Yang Tao, Nguyen Duy Bac, Nguyen Van Ba, Quynh-Anh Le, Van-Huy Pham \& Dinh-Toi Chu

Correction to: Scientific Reports https://doi.org/10.1038/s41598-019-39710-4, published online 28 February 2019

The original version of this Article contained an error in Affiliation 10, which was incorrectly given as 'AI Lab, Faculty of Information Technology, Ton Duc Thang University, Ho Chi Minh City, Vietnam, Ho Chi Minh City, Vietnam. The correct affiliation is listed below:

AI Lab, Faculty of Information Technology, Ton Duc Thang University, Ho Chi Minh City, Vietnam

This error has now been corrected in the HTML and PDF versions of the Article.

(c) Open Access This article is licensed under a Creative Commons Attribution 4.0 International License, which permits use, sharing, adaptation, distribution and reproduction in any medium or format, as long as you give appropriate credit to the original author(s) and the source, provide a link to the Creative Commons license, and indicate if changes were made. The images or other third party material in this article are included in the article's Creative Commons license, unless indicated otherwise in a credit line to the material. If material is not included in the article's Creative Commons license and your intended use is not permitted by statutory regulation or exceeds the permitted use, you will need to obtain permission directly from the copyright holder. To view a copy of this license, visit http://creativecommons.org/licenses/by/4.0/.

(C) The Author(s) 2019 